

\title{
EcoMnOx, a Biosourced Catalyst for Selective Aerobic Oxidative Cleavage of Activated 1,2-Diols
}

\author{
Vincent Escande, Chun Ho Lam, Claude Grison, Paul Anastas
}

\section{To cite this version:}

Vincent Escande, Chun Ho Lam, Claude Grison, Paul Anastas. EcoMnOx, a Biosourced Catalyst for Selective Aerobic Oxidative Cleavage of Activated 1,2-Diols. ACS Sustainable Chemistry \& Engineering, 2017, 5 (4), pp.3214 - 3222. 10.1021/acssuschemeng.6b02979 . hal-01937819

\section{HAL Id: hal-01937819 \\ https://hal.umontpellier.fr/hal-01937819}

Submitted on 19 Feb 2021

HAL is a multi-disciplinary open access archive for the deposit and dissemination of scientific research documents, whether they are published or not. The documents may come from teaching and research institutions in France or abroad, or from public or private research centers.
L'archive ouverte pluridisciplinaire HAL, est destinée au dépôt et à la diffusion de documents scientifiques de niveau recherche, publiés ou non, émanant des établissements d'enseignement et de recherche français ou étrangers, des laboratoires publics ou privés. 


\title{
EcoMnOx, a Biosourced Catalyst for Selective Aerobic Oxidative Cleavage of Activated 1,2-Diols
}

\author{
Vincent Escande, ${ }^{*},+\neq \odot$ Chun Ho Lam, ${ }^{\dagger}$ Claude Grison, ${ }^{*}$ and Paul T. Anastas ${ }^{*}, \dagger, \|, \S$ \\ ${ }^{\dagger}$ Center for Green Chemistry \& Green Engineering at Yale and "School of Forestry and Environmental Studies, Yale University, 195 \\ Prospect Street, New Haven, Connecticut 06515, United States \\ ${ }^{\ddagger}$ Laboratory of Bio-Inspired Chemistry and Ecological Innovations, ChimEco, UMR 5021 CNRS-UM, Cap Delta, 1682 Rue de la \\ Valsière, 34790 Grabels, France \\ ${ }^{\S}$ Department of Chemistry, Yale University, 225 Prospect Street, New Haven, Connecticut 06511, United States
}

\begin{abstract}
A novel catalyst, EcoMnOx, was prepared from waste biomass of Mn-hyperaccumulating plants. The valorization of this Mn-rich biomass is an alternative to its costly usual disposing and provides a new source of $\mathrm{Mn}$. Extracted metal ions, including $\mathrm{Mn}^{2+}$, were oxidized in mild conditions by $\mathrm{H}_{2} \mathrm{O}_{2} / \mathrm{NaOH}$ to afford EcoMnOx, as a polymetallic oxide material containing from 8.9 to 14.1 wt \% Mn. Spectroscopic studies of this material revealed the presence of Mn layered mixed oxides, rich in $\mathrm{Mn}^{\mathrm{IV}}$ along with $\mathrm{Mn}^{\mathrm{III}}$ and $\mathrm{Mn}^{\mathrm{II}}$ species. EcoMnOx catalytic properties were assessed in the aerobic oxidative cleavage of 1,2-diols, under atmospheric

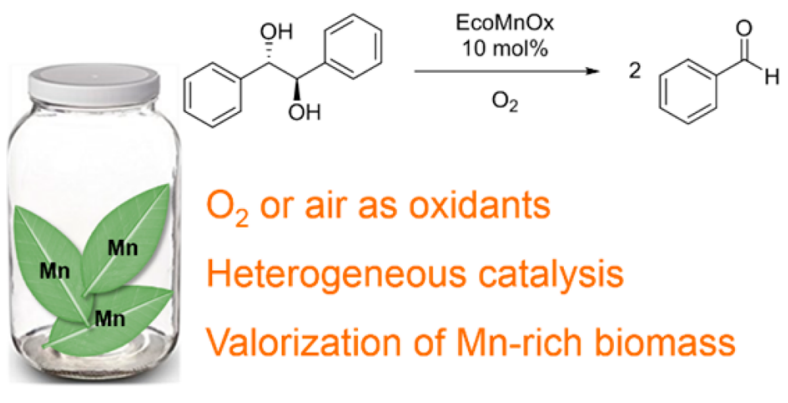
pressure of $\mathrm{O}_{2}$ or air. With only $10 \mathrm{~mol} \% \mathrm{Mn}$, up to complete conversions were obtained on activated benzylic and allylic diols, with excellent selectivity toward aldehydes or ketones (9899\%). Moreover, because of its heterogeneous nature, the catalyst can be removed easily by filtration, and reapplied for a minimum of six successive runs without any loss of activity. Finally, E-factor analysis showed the EcoMnOx generates 4 to 17 times less waste compared to classical reagents such as $\mathrm{NaIO}_{4}$ and $\mathrm{Pb}(\mathrm{OAc})_{4}$, respectively, highlighting the sustainable assets of this new heterogeneous catalyst.
\end{abstract}

KEYWORDS: Heterogeneous catalysis, Manganese oxide, Glycol cleavage, Ecocatalysis, Phytoextraction, Metal recycling

\section{INTRODUCTION}

Sustaining global population growth is one of the major upcoming challenges. According to the United Nations, the world population is expected to rise rapidly from the current 7.5 to 11.2 billion by the end of this century. ${ }^{1}$ Population growth and the consequent increased urbanization inevitably trigger a rise in demand of natural resources, such as energy, water, and minerals. Even with a shift toward sustainable energy production modes, building the necessary infrastructures (such as wind turbines or solar panels) will require high quantities of metals, ranging from base metals to rare earth elements, which will be sequestered for decades. At the same time, global population growth will lead to an increased demand in consumer goods, such as personal electronic devices, likely to exacerbate this forthcoming metals scarcity. As a result, base metals demand is currently increasing by $5 \%$ annually, such that metal production for the next 15 years will need to match that from the start of humanity up to the current time. ${ }^{2}$ This growing need for metals is also often decoupled from local production, stressing the risks of geopolitical tensions. For example, it has been stated that European industries consume more than $20 \%$ of the global production of metals, whereas European mines produce only $1.5 \%$ of iron and aluminum. ${ }^{2,3}$
Addressing future metal scarcity will suppose a necessary evolution of production and consumption habits, as well as a crucial improvement of current metals recycling rate. This can be dealt with the optimization of existing recycling processes, but also with the valorization of metal-rich wastes, unexploited until now.

Among these underestimated metal-rich wastes, ${ }^{4-6}$ biomass from phytoextraction crops is very promising. Phytoextraction is an emerging biotechnology using plants to remove contaminants, including metal pollutants from soils. ${ }^{7-10}$ Specific plants, named "hyperaccumulators" can uptake and store unusually high amounts of metal ions from the soil, achieving progressive decontamination of metal-polluted sites, like former mining areas. After accumulation, biomass from hyperaccumulators is harvested to avoid a new release of metal pollutants after plant death. However, the resulting metal enriched biomass is usually treated as a toxic waste, which induces a supplementary cost upon its disposal-a practice that is detrimental to the implementation of this ecofriendly 



Phytoextraction of soils after mining operations
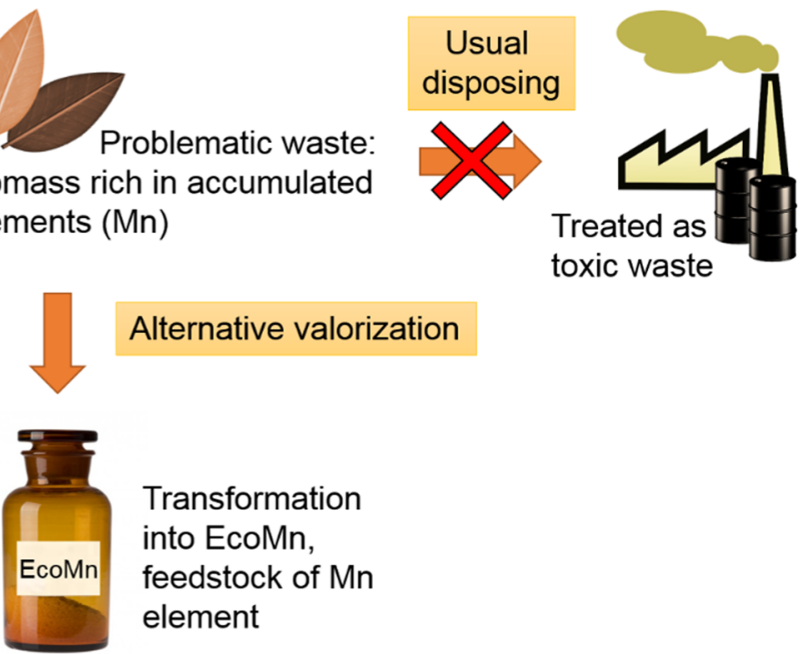

Figure 1. EcoMn production as alternative valorization of Mn-rich biomass from phytoextraction crops.

biotechnology. More importantly, disposing these valuable metals is even more regrettable, especially in view of the aforementioned metal shortages. ${ }^{11,12}$ In order to overcome this situation, attempts of valorization of this metal-rich biomass have recently emerged. ${ }^{13}$

Ecocatalysis is a new strategy to valorize metal-rich biomass as a source of metal species for chemical catalysis. ${ }^{14-17}$ As catalysis requires low amounts of metal (usually about a few mole percent) while promoting the synthesis of highly valuable compounds, the concept is potentially cost-effective enough to ensure its development on a large scale. Previous works have revealed the possibility of producing a manganese-rich material, starting from biomass of Mn-hyperaccumulating plants. The resulting material, named EcoMn, was used in organic synthesis directly as catalyst, or as source of $\mathrm{Mn}$ for producing more elaborate catalysts (Figure 1). ${ }^{18,19}$ Manganese displays appealing properties for catalysis, thanks to its multiple stable oxidation states and its low toxicity. ${ }^{20}$ Consequently, the use of manganese in industrial catalytic processes is expected to increase, as a substitute for precious metals or toxic elements. $^{21-23}$

Herein, we describe the synthesis of EcoMnOx, a new material rich in $\mathrm{Mn}$ oxides, which is made from EcoMn starting with Mn-hyperaccumulating plants. Study of the oxidizing properties of this material revealed excellent catalytic performances for aerobic oxidative cleavage of activated 1,2-diols. This reaction is usually performed with stoichiometric reagents, such as sodium periodate or lead tetraacetate, producing large amounts of toxic byproducts. Classical reaction conditions for oxidative cleavage of 1,2-diols are thus challenged by current standards of green chemistry. ${ }^{24,25}$ Although catalytic alternatives have been proposed recently, they suffer from several drawbacks, as these catalysts are either based on precious metals or are homogeneous and not reusable. ${ }^{26,27}$ The heterogeneous nature of the EcoMnOx catalyst and its reuse are thus key advantages, combined to the use of $\mathrm{O}_{2}$ or air as benign oxidant. This $\mathrm{Mn}$ catalyst prepared by valorization of waste biomass provides thus an efficient and sustainable alternative to previous methods of 1,2-diols oxidative cleavage.

\section{EXPERIMENTAL SECTION}

Materials and Methods. All commercially available chemicals were used as received. Solvents were purchased from Fisher Scientific and were of analytical grade; meso-hydrobenzoin (99\%), $(R, R)$ hydrobenzoin (99\%), cis-1,2-cyclohexanediol (99\%), 2,3-diphenyl-2,3butanediol (>90\%), and benzopinacol (99\%) were supplied by SigmaAldrich. Noncommercially available 1,2-diols were prepared by reduction of corresponding commercial diketones (purchased from Fisher Scientific), according to a known procedure. ${ }^{28}$

Characterization. ICP-AES measurements were performed using the PerkinElmer Optima 3000. Samples of $10 \mathrm{mg}$ were digested and dissolved in $2 \% \mathrm{HNO}_{3}$ acid and were quantified against external standards. SEM analyses were performed using the Hitachi SU-70 field emission microscope. Samples were predried in vacuum overnight and were examined with a $10 \mathrm{kV}$ bean power under ultrahigh vacuum without surface treatment. Energy-dispersive X-ray spectroscopy analysis (EDX) was performed using a Zeiss EVO HD15 microscope coupled with an Oxford X-MaxN EDX detector. XRPD measurements were performed on a Rigaku SmartLab X-ray diffractometer equipped with a $\mathrm{Cu}$ line-focus sealed tube and a NaI SC70 scintillation detector. Measurements were made with a $40 \mathrm{kV}, 44 \mathrm{~mA}$ beam, with an incident slit of $2 / 3^{\circ}$ and a length limiting slit of $5.00 \mathrm{~mm}$, in the range $2 \theta$ from $10^{\circ}$ to $90^{\circ}$ locked couple scan type, a step size of $0.05^{\circ}$, and a scan speed of $10.33^{\circ} / \mathrm{min}$. XPS analysis was performed using a ThermoScientific ESCALAB 250 instrument. Spectra were collected using a monochromatic $\mathrm{Al} \mathrm{X}$-ray source. A low energy electron flood and top-side contact were used for charge neutralization. Survey spectra were collected using a pass energy of $150 \mathrm{eV}$. Multiplex composition scans were acquired with $20 \mathrm{eV}$ pass energy. FTIR spectra were recorded on a FTIR/Raman Thermo Nicolet 6700 spectrometer, in ATR mode. All dynamic light scattering (DLS) samples were suspended in methanol $(1 \mathrm{mg} / 3 \mathrm{~mL})$ and were sonicated for $5 \mathrm{~min}$ prior analysis. DLS was performed at an angle of $90^{\circ}$ (ALV-5000, ALV-GmbH) using an incident laser of wavelength $532 \mathrm{~nm}$ (coherent). Thirty runs were recorded per sample, with a duration of $30 \mathrm{~s}$ per run. All DLS measurements were carried out at room temperature. Reaction products were characterized by ${ }^{1} \mathrm{H} /{ }^{13} \mathrm{C}$ NMR spectroscopy and by GC, by comparison of their retention times with those of pure standards, and analytical data were in accordance with those previously published. NMR characterization was performed with an Agilent DD2 $400 \mathrm{MHz}$ NMR spectrometer. GC were recorded on a Shimadzu GC-2010 Plus, equipped with an Agilent J\&W GC column, DB-5, $60 \mathrm{~m} \times 0.25 \mathrm{~mm} \times 0.25 \mu \mathrm{m}$, using He as carrier gas, with a flame ionization detector (FID). All analyses were performed including dodecane as internal standard.

Preparation of EcoMn. EcoMn was prepared from biomass of the Mn-hyperaccumulating plant Grevillea exul subsp. rubiginosa (Proteaceae), by calcination, acidic extraction then concentration. Grevillea exul subsp. rubiginosa is a native plant from New Caledonia, grown on mining sites of this subtropical Pacific island, for phytoextraction 
Table 1. ICP-AES Analysis of EcoMnOx Compared to Starting EcoMn

\begin{tabular}{|c|c|c|c|c|c|c|c|c|}
\hline element wt \% $( \pm \mathrm{sd})$ & $\mathrm{Fe}$ & $\mathrm{Mn}$ & $\mathrm{Ni}$ & $\mathrm{Ca}$ & $\mathrm{Mg}$ & $\mathrm{Al}$ & $\mathrm{Na}$ & $\mathrm{K}$ \\
\hline EcoMn & $0.9( \pm 0.008)$ & $6.7( \pm 0.04)$ & $0.04( \pm 0.0004)$ & $10.4( \pm 0.2)$ & $5.3( \pm 0.09)$ & $0.2( \pm 0.02)$ & $2.0( \pm 0.1)$ & $4.3( \pm 0.008)$ \\
\hline EcoMnOx & $0.3( \pm 0.006)$ & $14.1( \pm 0.4)$ & $\mathrm{nd}^{a}$ & $28.2( \pm 0.2)$ & $28.7( \pm 0.3)$ & $\mathrm{nd}^{a}$ & $0.5( \pm 0.09)$ & $\mathrm{nd}^{a}$ \\
\hline
\end{tabular}

${ }^{a}$ Not detected.

purposes. Details of the procedure and EcoMn characterization were reported in previous publications. ${ }^{18,19}$

Preparation of EcoMnOx. A solution of EcoMn (0.9 mmol Mn) was prepared by dissolution in $10 \mathrm{~mL}$ of deionized water. Under stirring at $400 \mathrm{rpm}, 0.28 \mathrm{~mL}(2.7 \mathrm{mmol})$ of a $30 \%$ aqueous solution of $\mathrm{H}_{2} \mathrm{O}_{2}$ were added in one portion. The resulting colorless solution was stirred for $5 \mathrm{~min}$, then $2 \mathrm{~mL}$ of $19 \mathrm{M} \mathrm{NaOH}(38 \mathrm{mmol})$ solution were added in one portion, and a black precipitate appeared immediately. After rinsing the sides of the flask with $10 \mathrm{~mL}$ of deionized water, the black catalyst suspension was stirred at $800 \mathrm{rpm}$ for $90 \mathrm{~min}$. The resulting suspension was filtered through a glass microfiber filter (Whatman, $1.6 \mu \mathrm{m}$ ) before washing it with 3 portions of $100 \mathrm{~mL}$ deionized water, followed by one portion of $50 \mathrm{~mL}$ ethanol. The black resulting solid should not be fully left dry before the end of all rinses to preserve its activity. The black solid, labeled as EcoMnOx hereafter, was then collected and dried in air, in an oven at $105^{\circ} \mathrm{C}$, for $18 \mathrm{~h}$.

Representative Procedure for Oxidative Cleavage of 1,2Diols. In a typical reaction, a mixture of meso-hydrobenzoin $(0.2$ $\mathrm{mmol})$, EcoMnOx (10 $\mathrm{mol} \% \mathrm{Mn})$, and 1-butanol $(1 \mathrm{~mL})$ was added in a $7 \mathrm{~mL}$ flask, under a balloon filled with $\mathrm{O}_{2}$. The mixture was heated to $100{ }^{\circ} \mathrm{C}$ under stirring (400 rpm) for $1 \mathrm{~h}$. After reaction, the mixture was cooled to room temperature, and the catalyst removed by filtration through PTFE membrane syringe filter (Millipore, $0.2 \mu \mathrm{m}$ ). Conversion and selectivity were determined by GC-FID, using dodecane as internal standard. Most reactions were repeated twice, and average values were given.

\section{RESULTS AND DISCUSSION}

Catalyst Preparation and Characterization. Synthesis of EcoMnOx was adapted from literature for preparing birnessitetype Mn oxides using $\mathrm{Mn}^{\mathrm{II}}$ salts. ${ }^{29,30}$ In our case, the source of $\mathrm{Mn}^{\mathrm{II}}$ ions was EcoMn prepared from Mn-hyperaccumulating plants and described in our previous works. ${ }^{18,19}$ These precedent studies showed that EcoMn was mainly constituted of polymetallic chlorides. EcoMnOx was prepared by rapid oxidation of a solution of EcoMn in aqueous $\mathrm{H}_{2} \mathrm{O}_{2} / \mathrm{NaOH}$, affording the new material as a precipitate, collected by filtration. Analysis of EcoMnOx by inductively coupled plasma atomic emission spectroscopy (ICP-AES) revealed that EcoMnOx was enriched in Mn (14.1 wt \%) compared to starting EcoMn (6.7 wt \%) (Table 1). This was due to EcoMnOx process of preparation, ensuring selective precipitation of insoluble oxides and hydroxides of $\mathrm{Mn}, \mathrm{Fe}, \mathrm{Ca}$ and $\mathrm{Mg}$. Metal enrichment also resulted from substitution of $\mathrm{Cl}$ (in starting EcoMn) by $\mathrm{O}$ (in resulting EcoMnOx), of lower molar mass and double valence. Comparison of several batches of EcoMn and their corresponding EcoMnOx, prepared from Grevillea exul subsp. rubiginosa harvested in different locations, showed some variation in elemental content (e.g., Mn: 8.9$14.1 \mathrm{wt} \%)$, due to the natural origin of the biomass feedstock (Table S1). Unless specified, all the following analyses and reactions were performed with the batch of EcoMnOx described in Table 1.

X-ray photoelectron spectroscopy (XPS) confirmed the oxide nature of EcoMnOx (Figure S1). An indication of $\mathrm{Mn}$ oxidation state was given by $\mathrm{Mn} 2 \mathrm{p}_{3 / 2}$ binding energy (642.8 $\mathrm{eV}$, Figure 2), characteristic of $\mathrm{Mn}^{\mathrm{IV}} \cdot{ }^{31} \mathrm{Mn} 3 \mathrm{~s}$ multiplet splitting supported this conclusion, while being less informative because



Figure 2. XPS Mn 2p peaks of EcoMnOx.

of obscuration of the peak by the interfering $\mathrm{Mg}$ peak (Figure S2). X-ray powder diffraction (XRPD) was performed to get complementary insights on EcoMnOx composition, as shown in Figure 3. Among detected crystalline species, the presence of



Figure 3. XRPD pattern of crystalline species detected in EcoMnOx.

birnessite was confirmed. Birnessite is a Mn layered mixed oxide, mainly composed of $\mathrm{Mn}^{\mathrm{IV}}$ oxide, including also $\mathrm{Mn}^{\mathrm{III}}$ and $\mathrm{Mn}^{\mathrm{II}}$ species. $^{32}$ As birnessite is often of low crystallinity, its weak signal does not typically reflect its actual proportion in the EcoMnOx catalyst. ${ }^{33}$ Interestingly, other $\mathrm{Mn}$ oxides with different oxidation states such as $\mathrm{CaMn}_{3} \mathrm{O}_{6} \quad\left(\mathrm{Mn}^{\mathrm{IV}}\right.$ and $\left.\mathrm{Mn}^{\mathrm{III}}\right),{ }^{34}$ groutite $\mathrm{MnO}(\mathrm{OH})\left(\mathrm{Mn}^{\mathrm{III}}\right)$, and $\mathrm{Mn}_{3} \mathrm{O}_{4}\left(\mathrm{Mn}^{\mathrm{III}}\right.$ and $\left.\mathrm{Mn}^{\mathrm{II}}\right)$, were also detected. While the complex polymetallic nature of EcoMnOx did not allow quantification of each $\mathrm{Mn}$ oxidation state because of interferences with other ions like $\mathrm{Fe}^{3+}$, these previous analyses demonstrated that $\mathrm{Mn}^{\mathrm{IV}}$ was preponderant based on XPS analysis, along with some $\mathrm{Mn}^{\mathrm{III}}$ 
and $\mathrm{Mn}^{\mathrm{II}}$ species present. These observations are in accordance with the characteristics of layered Mn oxides such as birnessite, whose $\mathrm{Mn}$ average oxidation degree is typically between +3.4 and $+3.99 .{ }^{35}$ Fourier transform infrared (FTIR, Figure 4) spectroscopy confirmed the attribution of this layered oxide structure for EcoMnOx, with a characteristic absorption at 400 $\mathrm{cm}^{-1} \cdot 36$



Figure 4. FTIR spectrum of EcoMnOx.

Morphological analysis by scanning electron microscopy (SEM) of EcoMnOx revealed the presence of structures of various sizes, within the range of $10-100 \mu \mathrm{m}$ (Figure 5a). These structures proved to be aggregates of smaller particles, as shown on Figure 5b. Dynamic light scattering (DLS) measurements were thus conducted after sonication of EcoMnOx, in order to fragment the aggregates, and revealed that average particle size was $103 \pm 91 \mathrm{~nm}$.

Catalyst Performance Evaluation. EcoMnOx was then tested as catalyst for oxidative cleavage of meso-hydrobenzoin as model substrate, under atmospheric pressure of $\mathrm{O}_{2}$. Solvent screening revealed that alcohols are the best solvents for the reaction (Table 2, entries 6-7). Previous works with manganese oxide reagents for 1,2-diols oxidative cleavage were only conducted with dichloromethane, in addition to requiring 40 equiv of $\mathrm{Mn}$ reagent toward substrate. ${ }^{37}$ As
Table 2. Solvent Screening for EcoMnOx-Catalyzed Oxidative Cleavage of meso-Hydrobenzoin ${ }^{a}$

$\begin{array}{clccc}\text { entry } & \text { solvent } & T\left[{ }^{\circ} \mathrm{C}\right] & \text { conversion 1a }[\%]^{b} & \text { selectivity } \mathbf{2 a}[\%]^{b, c} \\ 1 & \text { acetonitrile } & 78 & 43 & >99 \\ 2 & \text { ethyl acetate } & 78 & 35 & >99 \\ 3 & \text { toluene } & 78 & 55 & >99 \\ 4 & \text { water } & 78 & 53 & >99 \\ 5 & \text { acetic acid } & 78 & 47 & >99 \\ 6 & \text { ethanol } & 78 & 61 & >99 \\ 7 & \text { 1-butanol } & 100 & 98 & >99\end{array}$

${ }^{a}$ Reaction conditions: meso-hydrobenzoin $1 \mathrm{a}(42.9 \mathrm{mg}, 0.2 \mathrm{mmol})$, EcoMnOx $(10 \mathrm{~mol} \% \mathrm{Mn}), 1 \mathrm{~mL}$ of solvent, $\mathrm{O}_{2}$ balloon, $1 \mathrm{~h}$. ${ }^{b}$ Conversion and selectivity were determined by GC using dodecane as internal standard. ${ }^{c}$ Ratio of yield of aldehyde to conversion as a percentage.

alcohols are among the greener solvents for organic synthesis, ${ }^{38,39}$ their use in this reaction is thus a valuable asset. With $10 \mathrm{~mol} \%$ EcoMnOx (based on Mn content), almost complete conversion (98\%) was obtained in $1 \mathrm{~h}$, in 1-butanol allowing heating to $100{ }^{\circ} \mathrm{C}$ (Table 2, entry 7). A complete selectivity toward benzaldehyde was observed, with no traces of benzoic acid or other oxidation byproducts. No aldehyde disproportionation was noticed, even after prolonged reaction times.

Different atmospheres were also surveyed to assess the role of $\mathrm{O}_{2}$. Even if $\mathrm{O}_{2}$ lead to shorter reaction times, oxidative cleavage of meso-hydrobenzoin was also possible under air, with the same conversion in $3 \mathrm{~h}$ (Table 3 , entries $1-2$ ). The absence of conversion under $\mathrm{N}_{2}$ confirmed that $\mathrm{O}_{2}$ acted as terminal oxidant in the reaction (Table 3, entry 3) $\mathrm{H}_{2} \mathrm{O}_{2}$ was also tried as an alternative to $\mathrm{O}_{2}$ for oxidative cleavage of 1,2-diols. Indeed, in a previous paper on alkene epoxidation with $\mathrm{NaHCO}_{3} / \mathrm{H}_{2} \mathrm{O}_{2}$ catalyzed by EcoMn, some cleavage of the substrates was described, probably resulting of the hydrolysis of the epoxide, then oxidation of the resulting 1,2-diol. ${ }^{19}$ However, when $\mathrm{H}_{2} \mathrm{O}_{2}$ was used in the present methodology, a complete decomposition of $\mathrm{H}_{2} \mathrm{O}_{2}$ was observed upon addition of the EcoMnOx catalyst, resulting in absence of conversion of mesohydrobenzoin (Table 3, entry 4). This decomposition can be attributed to the $\mathrm{Mn}$ oxides in EcoMnOx, known to decompose $\mathrm{H}_{2} \mathrm{O}_{2}$ into $\mathrm{H}_{2} \mathrm{O}$ and $\mathrm{O}_{2}{ }^{40}$ This result showed that the active species in EcoMnOx were different from those involved in the epoxidation/cleavage of alkenes catalyzed by EcoMn, which in a



b



Figure 5. SEM images of EcoMnOx. 
Table 3. meso-Hydrobenzoin Oxidative Cleavage with Different Mn Oxide Catalysts and Atmospheres ${ }^{a}$



$1 a$

2a

\begin{tabular}{|c|c|c|c|c|c|}
\hline entry & catalyst & atmosphere & $\begin{array}{c}t \\
{[\mathrm{~h}]}\end{array}$ & $\begin{array}{l}\text { conversion } \\
\text { 1a }[\%]^{b}\end{array}$ & $\begin{array}{l}\text { selectivity } \\
\text { 2a }[\%]^{b, c}\end{array}$ \\
\hline 1 & EcoMnOx & $\mathrm{O}_{2}$ & 1 & 98 & $>99$ \\
\hline 2 & EcoMnOx & air & 3 & 98 & $>99$ \\
\hline 3 & EcoMnOx & $\mathrm{N}_{2}$ & 1 & 2 & \\
\hline $4^{d}$ & EcoMnOx & $\mathrm{N}_{2}$ & 1 & 0 & \\
\hline 5 & $\begin{array}{l}\text { 《synthetic» } \\
\text { EcoMnOx }\end{array}$ & $\mathrm{O}_{2}$ & 1 & 99 & $>99$ \\
\hline 6 & none & $\mathrm{O}_{2}$ & 1 & 0 & \\
\hline 7 & commercial $\mathrm{MnO}_{2}$ & $\mathrm{O}_{2}$ & 1 & 5 & $>99$ \\
\hline 8 & $\begin{array}{l}\text { commercial } \\
\text { activated } \mathrm{MnO}_{2}\end{array}$ & $\mathrm{O}_{2}$ & 1 & 5 & $>99$ \\
\hline
\end{tabular}

${ }^{a}$ Reaction conditions: meso-hydrobenzoin 1a (42.9 mg, $\left.0.2 \mathrm{mmol}\right)$, catalyst $(10 \mathrm{~mol} \% \mathrm{Mn})$, 1-butanol $(1 \mathrm{~mL})$, gas balloon, $100{ }^{\circ} \mathrm{C}$. ${ }^{b}$ Conversion and selectivity were determined by GC using dodecane as an internal standard. 'Ratio of yield of aldehyde to conversion as a percentage. ${ }^{d}$ Reaction performed in the presence of $\mathrm{H}_{2} \mathrm{O}_{2}$ (30 wt \% aqueous solution, $3.0 \mathrm{mmol}) .{ }^{e}$ Catalyst prepared according the same protocol than EcoMnOx, but with commercial $\mathrm{MnCl}_{2} \cdot 4 \mathrm{H}_{2} \mathrm{O}$.

the latter case were mainly $\mathrm{Mn}^{2+}$ ions with probably only transient formation of higher oxidation states.

In another control experiment, a "synthetic EcoMnOx", prepared in the same conditions than the biosourced catalyst, but starting from only pure $\mathrm{MnCl}_{2} \cdot 4 \mathrm{H}_{2} \mathrm{O}$, gave an almost complete conversion (99\%) with complete selectivity toward benzaldehyde (Table 3, entry 5). This result, combined to the absence of conversion without catalyst (Table 3, entry 6), confirmed that $\mathrm{Mn}$ oxides present in EcoMnOx were indeed the active species, and that other metal elements detected in EcoMnOx were only spectator elements. For this reason, even if some variation in elemental content was noted between several batches of EcoMnOx prepared from Grevillea exul subsp. rubiginosa harvested in different locations (Table S1), all the batches of EcoMnOx showed the same catalytic performances when used in $10 \mathrm{~mol} \% \mathrm{Mn}$ for oxidative cleavage of meso-hydrobenzoin.

As XPS and XRPD analyses have showed that Mn was mainly present under the oxidation state $\mathrm{Mn}^{\mathrm{IV}}$ in EcoMnOx, we tested $\mathrm{MnO}_{2}$ and activated $\mathrm{MnO}_{2}$, both commercial, as catalysts in the reaction. While in both cases a complete selectivity toward benzaldehyde $2 \mathrm{a}$ was observed, the conversion was only $5 \%$ (Table 3, entries 7-8). While EcoMnOx, $\mathrm{MnO}_{2}$ and activated $\mathrm{MnO}_{2}$ have a common content in $\mathrm{Mn}^{\mathrm{IV}}$ oxide, previous studies have extensively showed that $\mathrm{Mn}^{\mathrm{IV}}$ oxides can exist under a wide variety of forms, with completely different catalytic activities. ${ }^{32}$ This could explain why EcoMnOx (and "synthetic EcoMnOx") was much more active than commercial $\mathrm{MnO}_{2}$, due to its unique structure, resulting of its particular preparation.

Upon optimizing reaction condition, we extended the substrate scope to explore the versatility of EcoMnOx as shown in Table 4. Like anti-1,2-diol 1a, the syn-1,2-diol $\mathbf{1 b}$ also cleaved efficiently with high selectivity (Table 4, entry 1 ), but in a slightly longer reaction time. Benzylic 1,2-diol 1c activated by electron-donating aromatic substituents was slightly more reactive than those substituted by electron-withdrawing groups such as $\mathbf{1 d}$ and 1e (Table 4, entries 2-4). However, cleavage of the latter ones was still performed with high conversion and in short reaction times. Among the diols surveyed, selectivity toward the corresponding aldehyde or ketone was always high $(\geq 98 \%)$, and overoxidized products such as carboxylic acids were not detected. Interestingly, 1,2-diols with secondary hydroxyl groups showed a higher reactivity than the tertiary ones (Table 4, entry 5), probably because of steric effects in the last case, affecting interaction with the catalyst. However, tertiary diols bearing highly activating substituents, like benzopinacol $1 \mathrm{~g}$, were still cleaved with a complete conversion (Table 4, entry 6). Reaction with a less activated, mixed benzylic-aliphatic 1,2-diol $\mathbf{1 h}$ yielded relatively little products even at prolonged reaction time, which indicated the method was highly selective toward dibenzylic diols (Table 4, entry 7). This particular selectivity was confirmed by the absence of conversion of cis-1,2-cyclohexanediol 1i (Table 4, entry 8). High conversions $(\geq 95 \%)$ were obtained with diverse activated 1,2-diols, like heterocyclic diol $\mathbf{1 j}$ (Table 4, entry 9) and allylic diol $\mathbf{1 k}$ (Table 4, entry 10), thereby extending the potential of the method. Since a difference in reaction times was observed between anti and syn diastereomers $\mathbf{1 a}$ and $\mathbf{1} \mathbf{b}$ respectively, a similar variation in reactivity should be probably noted for the pure diastereomers of the other substrates, used here as mixtures of variable syn/anti ratios.

In order to investigate the kinetic aspects of the reaction, time-dependent studies were conducted. A EcoMnOx-catalyzed kinetic experiment with meso-hydrobenzoin revealed a first order rate equation toward substrate, with a rate constant of $5.48 \mathrm{~h}^{-1}$ (Figure 6). When the catalyst was removed by filtration shortly after the beginning of the kinetic experiment and then the reaction continued with the filtrate, no further conversion was observed, confirming the heterogeneous nature of the catalytic species (Figure 7).

The heterogeneous nature of EcoMnOx enables catalyst recycling for multiple runs: for example, after oxidative cleavage of benzopinacol $1 \mathrm{~g}$, EcoMnOx was separated by centrifugation, washed with ethanol and then dried. The recovered catalyst was reapplied for an identical experiment. The procedure was repeated six successive times, and the catalyst showed no apparent loss of activity (Figure 8).

The characterization of another batch of EcoMnOx was performed after reaction, in order to assess the stability of the catalyst. The content in metal elements remained virtually unmodified before and after oxidative cleavage of mesohydrobenzoin (Table S2). Morphological analysis by SEM showed a constant size of aggregates before and after reaction (Figure S3). According to energy-dispersive X-ray (EDX) analysis, the oxygen content of EcoMnOx stayed the same (see Figure S4), which revealed that the oxide character of the material remained unmodified after reaction.

Finally, comparison with traditional reagents $\mathrm{NaIO}_{4}$ and $\mathrm{Pb}(\mathrm{OAc})_{4}$ highlighted the sustainability assets of this new method, especially for cleavage of activated 1,2-diols (Table 5). Not only the EcoMnOx-catalyzed version was performed in nontoxic 1-butanol, compared to classical dichloromethane and benzene, but the only byproduct formed with this method was water, whereas traditional reagents produce stoichiometric quantities of toxic wastes. In addition, the heterogeneous catalytic nature of $\mathrm{EcoMnOx}$ allowed its reuse in at least six successive runs without loss of activity. Finally, the combination of these characteristics was summarized in the E-factor value, 
Table 4. Scope of the EcoMnOx-Catalyzed Aerobic Oxidative Cleavage of 1,2-Diols ${ }^{a}$

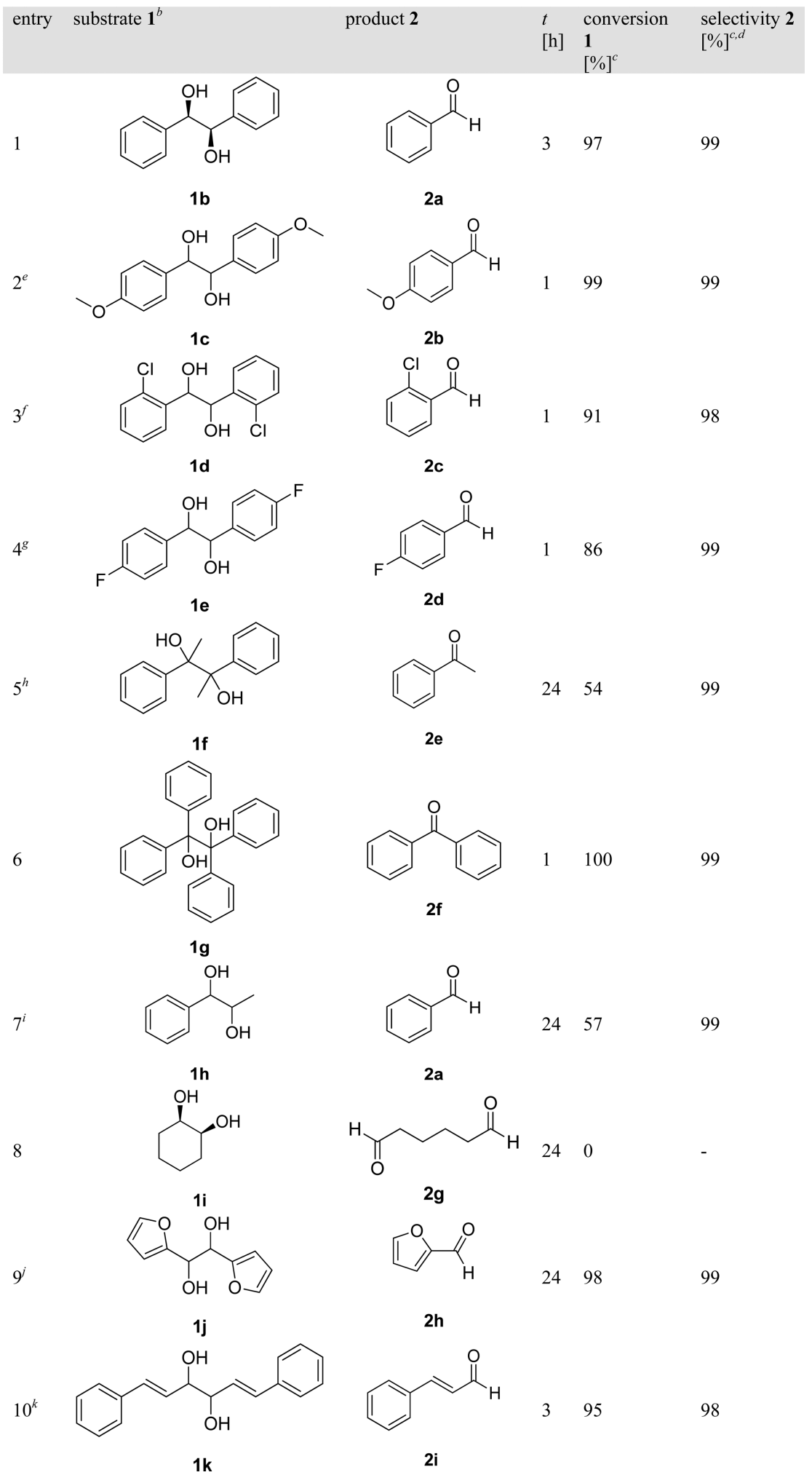

${ }^{a}$ Reaction conditions: substrate $(0.2 \mathrm{mmol}), \mathrm{EcoMnOx}(10 \mathrm{~mol} \% \mathrm{Mn}), 1$-butanol $(1 \mathrm{~mL}), \mathrm{O}_{2}$ balloon, $100{ }^{\circ} \mathrm{C} .{ }^{b}$ Unless specified, the starting diols bearing two stereogenic centers were used as variable mixtures of diastereomers, with syn/anti ratio determined by ${ }^{1} \mathrm{H}$ NMR. ${ }^{c}$ Determined by GC using dodecane as an internal standard. ${ }^{d}$ Ratio of yield of aldehyde or ketone to conversion as a percentage. ${ }^{e}$ Diol used in diastereomeric ratio syn/

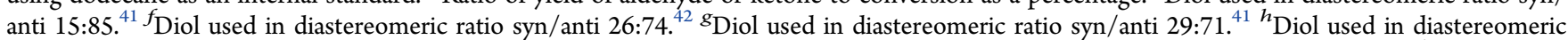
ratio syn/anti 54:46. ${ }^{41}{ }^{i}$ Diol used in diastereomeric ratio syn/anti 30:70. ${ }^{43,44}$ Diol used in diastereomeric ratio syn/anti $42: 58 .{ }^{42} k^{k}$ Diol used in diastereomeric ratio syn/anti $52: 48 .^{42}$

assessing the ratio of amounts of waste formed by unit of product. $^{45}$ With a E-factor of 0.8 for meso-hydrobenzoin oxidative cleavage, the EcoMnOx-catalyzed method produced 4-17 times less waste than $\mathrm{Pb}(\mathrm{OAc})_{4}$ and $\mathrm{NaIO}_{4}$, respectively. 




Figure 6. Kinetic study of the aerobic oxidative cleavage of mesohydrobenzoin, catalyzed by EcoMnOx. Reaction conditions: mesohydrobenzoin $(0.2 \mathrm{mmol}), \mathrm{EcoMnOx}(10 \mathrm{~mol} \% \mathrm{Mn})$, 1-butanol (1 $\mathrm{mL}), \mathrm{O}_{2}$ balloon, $100{ }^{\circ} \mathrm{C} . \mathrm{C}(0)$ original concentration of substrate; $C(t)$ concentration of substrate at time $t$.



Figure 7. Effect of catalyst filtration on the aerobic oxidative cleavage of meso-hydrobenzoin. Reaction conditions: meso-hydrobenzoin $(0.2$ $\mathrm{mmol}$ ), EcoMnOx (10 mol \% Mn), 1-butanol ( $1 \mathrm{~mL}), \mathrm{O}_{2}$ balloon, 100 ${ }^{\circ} \mathrm{C}$. After $0.08 \mathrm{~h}, \mathrm{EcoMnOx}$ was removed by filtration then the reaction was continued with the filtrate. Yield of benzaldehyde was determined by GC using dodecane as an internal standard.



Figure 8. Reuse of EcoMnOx catalyst in successive reaction runs. Reaction conditions: benzopinacol $(0.2 \mathrm{mmol}), \mathrm{EcoMnOx}(10 \mathrm{~mol} \%$ $\mathrm{Mn})$, 1-butanol $(1 \mathrm{~mL}), \mathrm{O}_{2}$ balloon, $100{ }^{\circ} \mathrm{C}, 1 \mathrm{~h}$. After reaction, the catalyst was recovered by centrifugation, rinsed with $2 \times 4 \mathrm{~mL}$ of ethanol and then dried in oven under air at $105^{\circ} \mathrm{C}$ for $2 \mathrm{~h}$. Yields were determined by GC using dodecane as an internal standard.
Table 5. Comparison of the EcoMnOx-Catalyzed Method with $\mathrm{NaIO}_{4}$ and $\mathrm{Pb}(\mathrm{OAc})_{4}$, on the Basis of Sustainability Characteristics

\begin{tabular}{llll} 
& \multicolumn{1}{c}{$\begin{array}{c}\text { EcoMnOx/ } \\
\mathrm{O}_{2}{ }^{a}\end{array}$} & \multicolumn{1}{c}{$\mathrm{NaIO}_{4}{ }^{b}$} & $\mathrm{~Pb}(\mathrm{OAc})_{4}{ }^{b}$ \\
solvent typically used & 1-butanol & dichloromethane & benzene \\
wastes formed & water & $\mathrm{NaIO}_{3}$ & $\mathrm{~Pb}(\mathrm{OAc})_{2}$ \\
$\begin{array}{l}\text { successive runs without } \\
\text { loss of activity }\end{array}$ & $\begin{array}{c}\geq 6 \text { (6 runs } \\
\text { tested })\end{array}$ & 1 & 1 \\
E-factor $(E)^{c}$ & 0.8 & 13.9 & 3.2
\end{tabular}

${ }^{a}$ See the SI for details of reaction conditions and calculations. ${ }^{b}$ Calculated for $90 \%$ yield in typical reaction conditions from ref 46 . ${ }^{c}$ meso-Hydrobenzoin oxidative cleavage was used as model reaction for E-factor calculations with the different methods.

\section{CONCLUSION}

In the face of metal shortages due to population growth and rapid urbanization, the EcoMn feedstock made from phytoextraction biomass serves as a novel, effective strategy to clean up and recycle $\mathrm{Mn}$ from mining waste. Through a simple process using readily available reagents, we turned this biosourced $\mathrm{Mn}$ feedstock into a new catalyst, EcoMnOx, that rivals the existing methodology for 1,2-diols oxidative cleavage. In mild reaction conditions, EcoMnOx catalyzed the aerobic oxidative cleavage of a range of activated 1,2-diols, with high conversion and selectivity. These promising results will motivate further mechanistic studies in order to determine the role of each $\mathrm{Mn}$ oxide species present in EcoMnOx, depending on their oxidation state and their possible cooperative catalytic effect. Considering the serious environmental concerns associated with some of the traditional reagents used for 1,2-diols oxidative cleavage, the heterogeneous nature of EcoMnOx catalyst, its possible reuse, and the formation of water as the sole byproduct while using $\mathrm{O}_{2}$ or air as benign oxidants in a green solvent confer strong sustainable advantages to this new method.

\section{ASSOCIATED CONTENT}

Experimental details, XPS spectra, ICP-AES analyses, SEM images, EDX spectra, GC chromatograms, and E-factor calculations (PDF)

\section{AUTHOR INFORMATION Corresponding Authors \\ *E-mail: vincent.escande@cnrs.fr \\ *E-mail: paul.anastas@yale.edu \\ ORCID $\odot$}

Vincent Escande: 0000-0003-3164-8128

Paul T. Anastas: 0000-0003-4777-5172

\section{Notes}

The authors declare no competing financial interest.

\section{ACKNOWLEDGMENTS}

V.E. gratefully acknowledges support from the French National Center for Scientific Research (CNRS). C.H.L. would like to thank the Gaylord and Dorothy Foundation for the fellowship support. Dr. Cyril Poullain is acknowledged for the cultivation 
and harvest of Mn-hyperaccumulating plants, as well as the New Caledonia authorities for supporting phytoextraction crops on mining sites. Dr. Stephen Golledge from University of Oregon is acknowledged for assistance with XPS analyzes. Dr. Yves-Marie Legrand from Institut Européen des Membranes is acknowledged for assistance with SEM and EDX analyses. Special thanks to Dr. Sara Hashmi at the Facility for Light Scattering at Yale University for her assistance and instrumentation support.

\section{REFERENCES}

(1) World Population Prospects: The 2015 Revision, Key Findings and Advance Tables, Working Paper No. ESA/P/WP.241; United Nations, Department of Economic and Social Affairs, Population Division, 2015.

(2) Vidal, O.; Goffe, B.; Arndt, N. Metals for a low-carbon society. Nat. Geosci. 2013, 6 (11), 894-896.

(3) European mineral statistics 2007-11; British Geological Survey: Keyworth, Nottingham, 2013.

(4) Rawlings, D. E.; Johnson, D. B. The microbiology of biomining: development and optimization of mineral-oxidizing microbial consortia. Microbiology 2007, 153 (2), 315-324.

(5) Widmer, R.; Oswald-Krapf, H.; Sinha-Khetriwal, D.; Schnellmann, M.; Böni, H. Global perspectives on e-waste. Environ. Impact Asses. 2005, 25 (5), 436-458.

(6) Wagner, T. P.; Raymond, T. Landfill mining: Case study of a successful metals recovery project. Waste Manage. (Oxford, U. K.) 2015, 45, 448-457.

(7) Ansari, A. A.; Gill, S. S.; Gill, R.; Lanza, G. R.; Newman, L. Phytoremediation. Management of environmental contaminants; Springer: New York, 2015; Vol. 1.

(8) Raskin, I.; Ensley, B. D. Phytoremediation of toxic metals: using plants to clean up the environment; John Wiley: New York, 2000.

(9) Singh, O. V.; Labana, S.; Pandey, G.; Budhiraja, R.; Jain, R. K. Phytoremediation: an overview of metallic ion decontamination from soil. Appl. Microbiol. Biotechnol. 2003, 61 (5-6), 405-412.

(10) Grison, C. Combining phytoextraction and ecocatalysis: a novel concept for greener chemistry, an opportunity for remediation. Environ. Sci. Pollut. Res. 2015, 22 (8), 5589-5591.

(11) Ernst, W. H. O. Phytoextraction of mine wastes - Options and impossibilities. Chem. Erde 2005, 65, 29-42.

(12) Vigil, M.; Marey-Perez, M. F.; Huerta, G. M.; Cabal, V. A. Is phytoremediation without biomass valorization sustainable? - Comparative LCA of landfilling vs. anaerobic co-digestion. Sci. Total Environ. 2015, 505, 844-850.

(13) van der Ent, A.; Baker, A. J. M.; Reeves, R. D.; Chaney, R. L.; Anderson, C. W. N.; Meech, J. A.; Erskine, P. D.; Simonnot, M. O.; Vaughan, J.; Morel, J. L.; Echevarria, G.; Fogliani, B.; Rongliang, Q.; Mulligan, D. R. Agromining: Farming for Metals in the Future? Environ. Sci. Technol. 2015, 49 (8), 4773-4780.

(14) Grison, C.; Escande, V.; Olszewski, T. K. Ecocatalysis: A New Approach Toward Bioeconomy. In Bioremediation and Bioeconomy; Prasad, M. N. V., Ed.; Elsevier: Amsterdam, 2016; pp 629-663.

(15) Escande, V.; Garoux, L.; Grison, C.; Thillier, Y.; Debart, F.; Vasseur, J. J.; Boulanger, C.; Grison, C. Ecological catalysis and phytoextraction: Symbiosis for future. Appl. Catal., B 2014, 146, 279288.

(16) Clavé, G.; Garoux, L.; Boulanger, C.; Hesemann, P.; Grison, C. Ecological Recycling of a Bio-Based Catalyst for Cu Click Reaction: a New Strategy for a Greener Sustainable Catalysis. ChemistrySelect 2016, 1 (7), 1410-1416.

(17) Clave, G.; Garel, C.; Poullain, C.; Renard, B. L.; Olszewski, T. K.; Lange, B.; Shutcha, M.; Faucon, M. P.; Grison, C. Ullmann reaction through ecocatalysis: insights from bioresource and synthetic potential. RSC Adv. 2016, 6 (64), 59550-59564.

(18) Escande, V.; Velati, A.; Garel, C.; Renard, B.-L.; Petit, E.; Grison, C. Phytoextracted mining wastes for ecocatalysis: Eco-Mn, an efficient and eco-friendly plant-based catalyst for reductive amination of ketones. Green Chem. 2015, 17 (4), 2188-2199.

(19) Escande, V.; Petit, E.; Garoux, L.; Boulanger, C.; Grison, C. Switchable Alkene Epoxidation/Oxidative Cleavage with $\mathrm{H} 2 \mathrm{O} 2$ / NaHCO3: Efficient Heterogeneous Catalysis Derived from Biosourced Eco-Mn. ACS Sustainable Chem. Eng. 2015, 3 (11), 27042715.

(20) Gerber, G. B.; Leonard, A.; Hantson, P. Carcinogenicity, mutagenicity and teratogenicity of manganese compounds. Critical Reviews in Oncology Hematology 2002, 42 (1), 25-34.

(21) Browne, W. R.; de Boer, J. W.; Pijper, D.; Brinksma, J.; Hage, R.; Feringa, B. L. Manganese-Catalyzed Oxidation with Hydrogen Peroxide. In Modern Oxidation Methods; Wiley-VCH Verlag GmbH \& Co. KGaA, 2010; pp 371-419.

(22) Manganese-Catalyzed Heterocycle Synthesis. In Economic Synthesis of Heterocycles: Zinc, Iron, Copper, Cobalt, Manganese and Nickel Catalysts; The Royal Society of Chemistry: 2014; pp 386-434.

(23) Freire, C.; Pereira, C.; Peixoto, A. F.; Fernandes, D. M. Sustainable Catalysis by Manganese Compounds: From Heterogeneous Molecular Complexes to Manganese-based (Nano)Materials. In Sustainable Catalysis: With Non-endangered Metals, Part 1; The Royal Society of Chemistry, 2016; pp 278-343.

(24) Anastas, P. T.; Heine, L. G.; Williamson, T. C. Green Chemical Syntheses and Processes: Introduction. In Green Chemical Syntheses and Processes; ACS Symposium Series Vol 767; Anastas, P. T., Heine, L. G., Williamson, T. C., Eds.; American Chemical Society: Washington, DC, 2000; pp 1-6.

(25) Anastas, P. T.; Williamson, T. C.; Hjeresen, D.; Breen, J. J. Promoting Green Chemistry Initiatives. Environ. Sci. Technol. 1999, 33 (5), 116A-119A

(26) Schmidt, A. K. C.; Stark, C. B. W. The Glycol Cleavage in Natural Product Synthesis: Reagent Classics and Recent Advances. Synthesis 2014, 46 (24), 3283-3308.

(27) Wong, A. W. H.; Shing, T. K. M., Glycol Cleavage Reactions. In Comprehensive Organic Synthesis II, second ed.; Knochel, P., Molander, G. A., Eds.; Elsevier: Amsterdam, 2014; Vol. 7, pp 801-817.

(28) Anju, K. S.; Ramakrishnan, S.; Thomas, A. P.; Suresh, E.; Srinivasan, A. 9,10,19,20-Tetraarylporphycenes. Org. Lett. 2008, 10 (24), 5545-5548.

(29) Feng, Q.; Yanagisawa, K.; Yamasaki, N. Transformation of manganese oxides from layered structures to tunnel structures. Chem. Commun. 1996, 14, 1607-1608.

(30) Feng, Q.; Yanagisawa, K.; Yamasaki, N. Synthesis of birnessitetype lithium manganese oxide. Nippon Seramikkusu Kyokai Gakujutsu Ronbunshi 1996, 104 (9), 897-899.

(31) Junta, J. L.; Hochella, M. F. Manganese (II) oxidation at mineral surfaces: A microscopic and spectroscopic study. Geochim. Cosmochim. Acta 1994, 58 (22), 4985-4999.

(32) Liu, J.; Durand, J. P.; Espinal, L.; Garces, L.-J.; Gomez, S.; Son, Y.-C.; Villegas, J.; Suib, S. L. Layered Manganese Oxides: Synthesis, Properties, and Applications. In Handbook of layered materials; Auerbach, S. M., Carrado, K. A., Dutta, P. K., Eds.; M. Dekker: New York, 2004; pp 475-508.

(33) Post, J. E. Manganese oxide minerals: Crystal structures and economic and environmental significance. Proc. Natl. Acad. Sci. U. S. A. 1999, 96 (7), 3447-3454.

(34) Hadermann, J.; Abakumov, A. M.; Gillie, L. J.; Martin, C.; Hervieu, M. Coupled cation and charge ordering in the CaMn3O6 tunnel structure. Chem. Mater. 2006, 18 (23), 5530-5536.

(35) Brock, S. L.; Duan, N. G.; Tian, Z. R.; Giraldo, O.; Zhou, H.; Suib, S. L. A review of porous manganese oxide materials. Chem. Mater. 1998, 10 (10), 2619-2628.

(36) Potter, R. M.; Rossman, G. R. Tetravalent Manganese Oxides Identification, Hydration, and Structural Relationships by InfraredSpectroscopy. Am. Mineral. 1979, 64 (11-1), 1199-1218.

(37) Ohloff, G.; Giersch, W. Conversion of Vicinal Diols into Dicarbonyl-Compounds by Manganese-Dioxide. Angew. Chem., Int. Ed. Engl. 1973, 12 (5), 401-402. 
(38) Henderson, R. K.; Jimenez-Gonzalez, C.; Constable, D. J. C.; Alston, S. R.; Inglis, G. G. A.; Fisher, G.; Sherwood, J.; Binks, S. P.; Curzons, A. D. Expanding GSK's solvent selection guide - embedding sustainability into solvent selection starting at medicinal chemistry. Green Chem. 2011, 13 (4), 854-862.

(39) Prat, D.; Wells, A.; Hayler, J.; Sneddon, H.; McElroy, C. R.; Abou-Shehada, S.; Dunn, P. J. CHEM21 selection guide of classicaland less classical-solvents. Green Chem. 2016, 18 (1), 288-296.

(40) Do, S.-H.; Batchelor, B.; Lee, H.-K.; Kong, S.-H. Hydrogen peroxide decomposition on manganese oxide (pyrolusite): Kinetics, intermediates, and mechanism. Chemosphere 2009, 75 (1), 8-12.

(41) Uchiyama, M.; Matsumoto, Y.; Nakamura, S.; Ohwada, T.; Kobayashi, N.; Yamashita, N.; Matsumiya, A.; Sakamoto, T. Development of a Catalytic Electron Transfer System Mediated by Transition Metal Ate Complexes: Applicability and Tunability of ElectronReleasing Potential for Organic Transformations. J. Am. Chem. Soc. 2004, 126 (28), 8755-8759.

(42) Li, J. T.; Lin, Z. P.; Qi, N.; Li, T. S. Pinacol Coupling of Aromatic Aldehydes and Ketones Using TiCl3-Al-EtOH Under Ultrasound Irradiation. Synth. Commun. 2004, 34 (23), 4339-4348.

(43) Freire, F.; Seco, J. M.; Quiñoá, E.; Riguera, R. Determining the Absolute Stereochemistry of Secondary/Secondary Diols by $1 \mathrm{H}$ NMR: Basis and Applications. J. Org. Chem. 2005, 70 (10), 3778-3790.

(44) Li, X.; Tanasova, M.; Vasileiou, C.; Borhan, B. Fluorinated Porphyrin Tweezer: A Powerful Reporter of Absolute Configuration for erythro and threo Diols, Amino Alcohols, and Diamines. J. Am. Chem. Soc. 2008, 130 (6), 1885-1893.

(45) Constable, D. J. C.; Curzons, A. D.; Cunningham, V. L. Metrics to 'green' chemistry-which are the best? Green Chem. 2002, 4 (6), 521-527.

(46) Vogel, A. I.; Furniss, B. S.; Vogel, A. I. Vogel's Textbook of practical organic chemistry, 5th ed.; Longman Scientific \& Technical: London, 1989; p xxviii. 